\title{
The High Temperature Wear Performance of TiN Coating Deposited by Magnetron Sputtering
}

\author{
Changjie Feng ${ }^{1, a^{*}}$, En Chen ${ }^{1, b}$ and Namei $\mathrm{Wu}^{1, \mathrm{c}}$ \\ ${ }^{1}$ School of Materials Science and Engineering, Nanchang Hangkong University, Nanchang, \\ 330063, China \\ achjfengniat@126.com, byhchenen@yahoo.com, ‘wunamei1626@126.com
}

\begin{abstract}
Keywords: magnetron sputtering; TiN coating; High temperature wear
Abstract. TiN coating was deposited by reactive magnetron sputtering method on 304 stainless steel. The surface morphology, cross-sectional microstructure, elements distribution and wear scar of the TiN coating were investigated by scanning electron microscopy, energy dispersive spectroscopy and optical microscopy. The friction-wear performance and mechanism of the coating in dry friction at different temperatures (RT, $200^{\circ} \mathrm{C}$ and $400^{\circ} \mathrm{C}$ ) were investigated. The results show that the wear resistance of the TiN coating is best at $200^{\circ} \mathrm{C}$ and the wear mechanism is abrasive wear.
\end{abstract}

\section{Introduction}

TiN coating is extensively used for the fields, such as various kinds of tool coating and decorative coating, etc. due to its high hardness, low friction coefficient and gorgeous metallic color. TiN belongs to $\mathrm{B} 1-\mathrm{NaCl}$ structure. Nitrogen atoms occupy interstitial positions of bcc crystal structure, which are composed of Titanium atoms.

Due to the TiN coating mostly deposited on substrate under non-equilibrium conditions, vacancy solid solution is formed easily ${ }^{[1-2]}$. When the nitrogen content is higher, TiN coating show compound properties. When the titanium content increases, the coating show the metal properties. Because of lubrication performance of titanium oxide and good adhesion ${ }^{[3,4]}$, TiN coating possessed excellent wear resistance ${ }^{[5]}$. Studies have shown that TiN coating would fail for oxidation formed at the temperature above $550^{\circ} \mathrm{C}$ or in the case of high speed milling ${ }^{[1,6-7]}$. By examining microstructure, elements distribution of the coating and wear scar, the influence of substrate temperature on friction and wear behaviors of TiN coating was investigated in dry friction at different temperatures.

\section{Experimental Details}

Experimental Materials and Methods. The experimental equipment is DM-3 magnetron sputtering system which was made by Shenyang Beiyu vacuum Co., LTD. TiN coating was deposited on 304 stainless steel with dimension of $20 \mathrm{~mm} \times 30 \mathrm{~mm} \times 2 \mathrm{~mm}$. The sputtering target material was pure titanium. Before deposition, the 304 stainless steel substrates were ground, polished, degreased and ultrasonically cleaned in absolute ethyl alcohol . In the vacuum chamber, the substrates were fixed on the rotational holder which rotation speed was controlled $20 \mathrm{rpm}$ during the deposition. The distance between the substrates and target was about $60 \mathrm{~mm}$. The parameters in the process of deposition were: temperature $280^{\circ} \mathrm{C}, \mathrm{Ar} / \mathrm{N}_{2}$ (with $99.99 \%$ purity) ratio 1:2, working pressure $0.8 \mathrm{~Pa}$ and working time $240 \mathrm{~min}$. The sputtering power of Ti target was controlled about $390 \mathrm{~W}$.

Analysis of Surface Topography and Elements Distribution. The surface topography of TiN coating and wear scar was observed by an environmental scanning electron microscope (quanta 
200). The cross-sectional microstructure of the coating was analyzed by the field-emission scanning electron microscope (Nova Nano SEM450). The composition was analyzed using an energy dispersive spectrometer(INCA 250X-Max 50).

Friction and Wear Tests. The tribological parameters of TiN coating were examined by an HT-1000 type friction and wear testing machine at different temperatures (RT, $200^{\circ} \mathrm{C}$ and $400^{\circ} \mathrm{C}$ ) under dry sliding condition. The friction pair was $\mathrm{Al}_{2} \mathrm{O}_{3}$ ball $5 \mathrm{~mm}$ in diameter. The parameters in friction and wear friction processes were: sliding time $5 \mathrm{~min}$, sliding radius $3 \mathrm{~mm}$, sliding speed 280 rpm, friction load $2.92 \mathrm{~N}$ and a relative humidity of $50-60 \%$.

The cross section of wear scar was observed by a Kh-7700 type optical microscope. Then use the following formula to calculate the wear volume-loss:

$$
\mathrm{V}=2 \pi \mathrm{rS}
$$

V: volume-loss; r: sliding radius; S: cross-sectional area of wear scar

\section{Results and Discussions}

Morphology and Composition of TiN Coating. Fig. 1(a) shows the surface of the TiN coating. The surface is relatively even without obvious defects. Fig. 1(b) shows the cross-sectional microstructure. The obvious columnar crystal was uniform and compact. EDS results show that the Ti content is 74.41 at. $\%$ and the $\mathrm{N}$ content is 74.41 at. $\%$ in the coating .

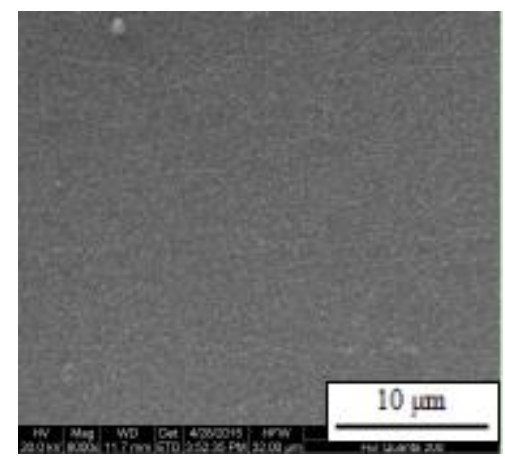

(a)surface morphology

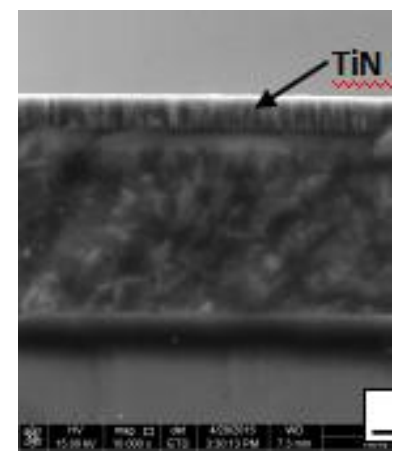

(b) cross section morphology

Fig.1 surface and cross section morphology of TiN coating

\section{Friction and Wear Performance}

The Friction Coefficient-time Curves at Different Temperatures. Fig. 2 shows that the friction coefficients with sliding time of the TiN coating against $\mathrm{Al}_{2} \mathrm{O}_{3}$ ball with constant load of $2.92 \mathrm{~N}$ at different temperatures. The friction process comprises two stages: running-in process and steady state. The frictional resistance enhanced rapidly in the beginning because of the interaction of asperities in the surface of the coating and the $\mathrm{Al}_{2} \mathrm{O}_{3}$ ball. Then the asperities were worn away and the oxide generated on the surface of the coating due to friction heat with sliding process. When the balance is achieved among all the process, sliding entered the steady stage. Because of the TiN oxidation of lower temperature, the running-in process requires a shorter time. The coefficient at RT, $200^{\circ} \mathrm{C}$ and $400^{\circ} \mathrm{C}$ was $0.75,0.45$ and 0.55 , respectively. By comparison, It was found the friction coefficient decreased with the increased of temperature within a certain range. When the temperature exceeded a certain value the friction coefficient increased . 


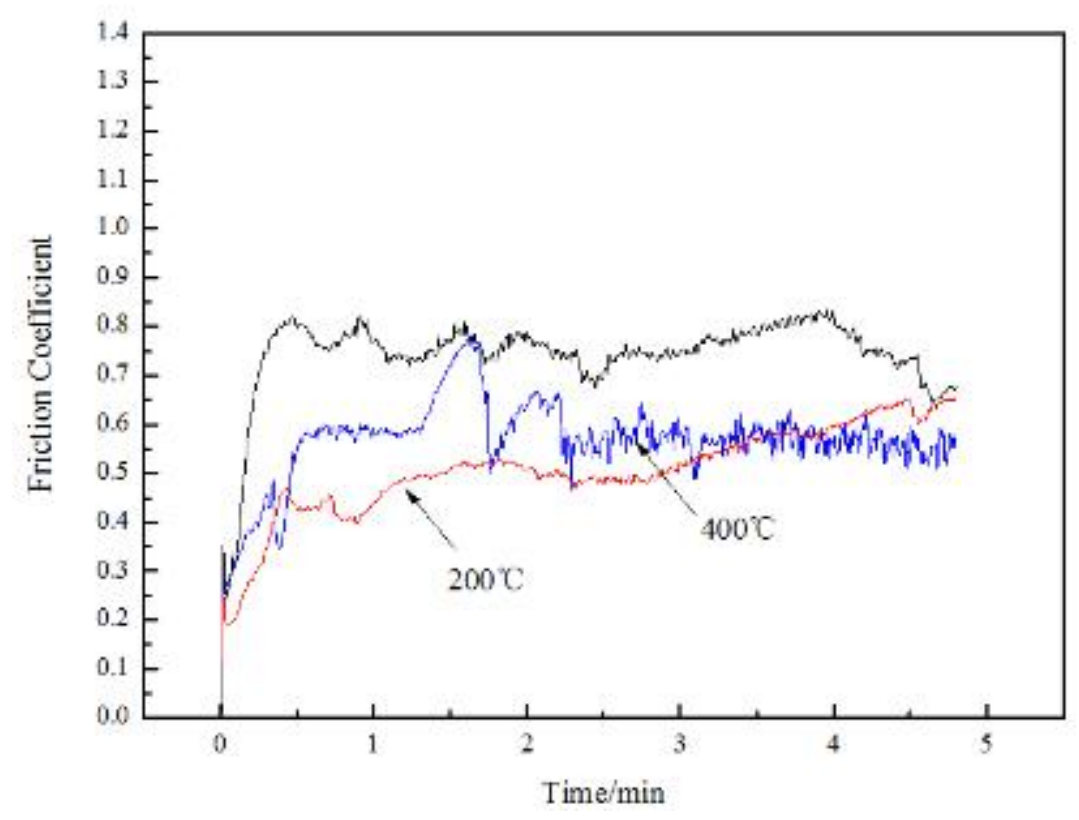

Fig.2 Function curve of friction coefficient and time of TiN coatings at different friction-wear temperatures

The Wear-volume at Different Temperatures. Fig.3 shows that the wear-volume of TiN coating at $200^{\circ} \mathrm{C}$ was $0.0269 \mathrm{~mm}^{3}$ and was smaller than that of the wear-volume at room temperature or $400^{\circ} \mathrm{C}$. It is obvious that the wear-volume decreases until $200^{\circ} \mathrm{C}$ is reached and then increases as the temperature increases. The wear volume is one of the indicators for wear-resistance, the wear-resistance of $\mathrm{TiN}$ is best at $200^{\circ} \mathrm{C}$.

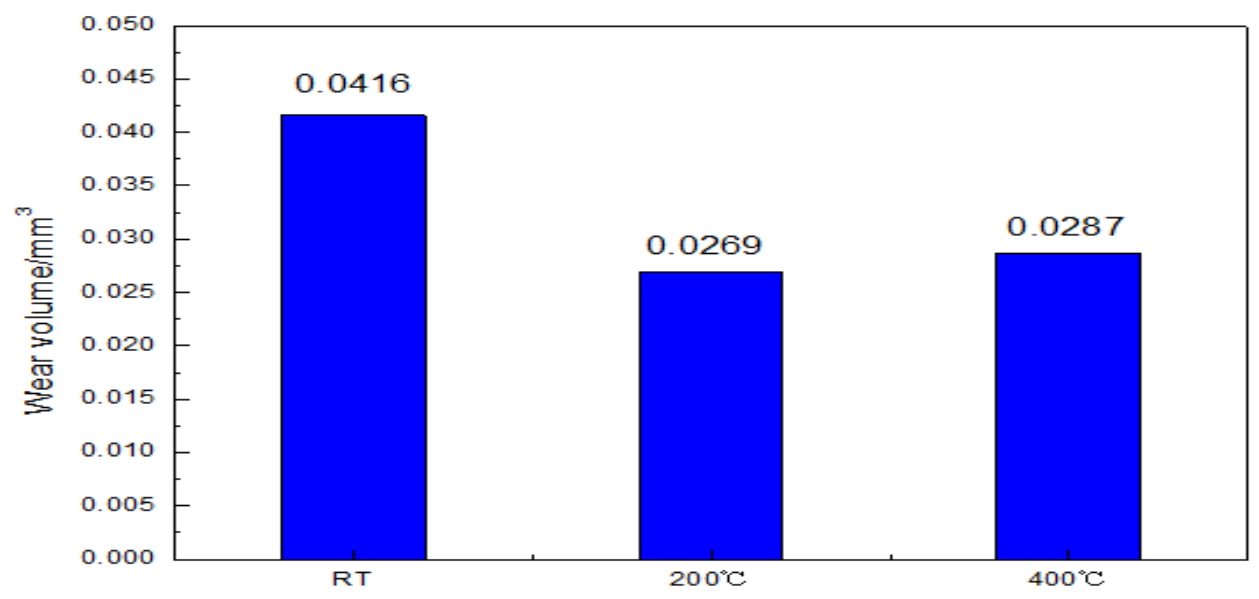

Fig.3 Wear volume comparison chart of TiN coatings at different friction-wear temperatures

Analysis of Wear Scar Morphology. As shown in Fig.4, TiN coating had different abrasion appearances at different temperatures, respectively. Fig.4(a) shows that plenty of white abrasion debris was distributed on the wear scar. The white debris contained Ti from TiN coating and a small amount of Fe from substrate determined by EDS. The emergence of Fe elements shows coating were worn out partly. The wear mechanism is mainly abrasive wear due to the fact that the wearing area surface had furrows at different temperatures. Friction coefficient and wear-volume increase at $400^{\circ} \mathrm{C}$ which were shown in the Fig. 2 and Fig.3. The intensity of TiN coating reduced, for TiN degraded and $\mathrm{Ti}$ united with oxygen. The wear mechanisms are mainly abrasion wear and oxidation wear at $400^{\circ} \mathrm{C}$. 

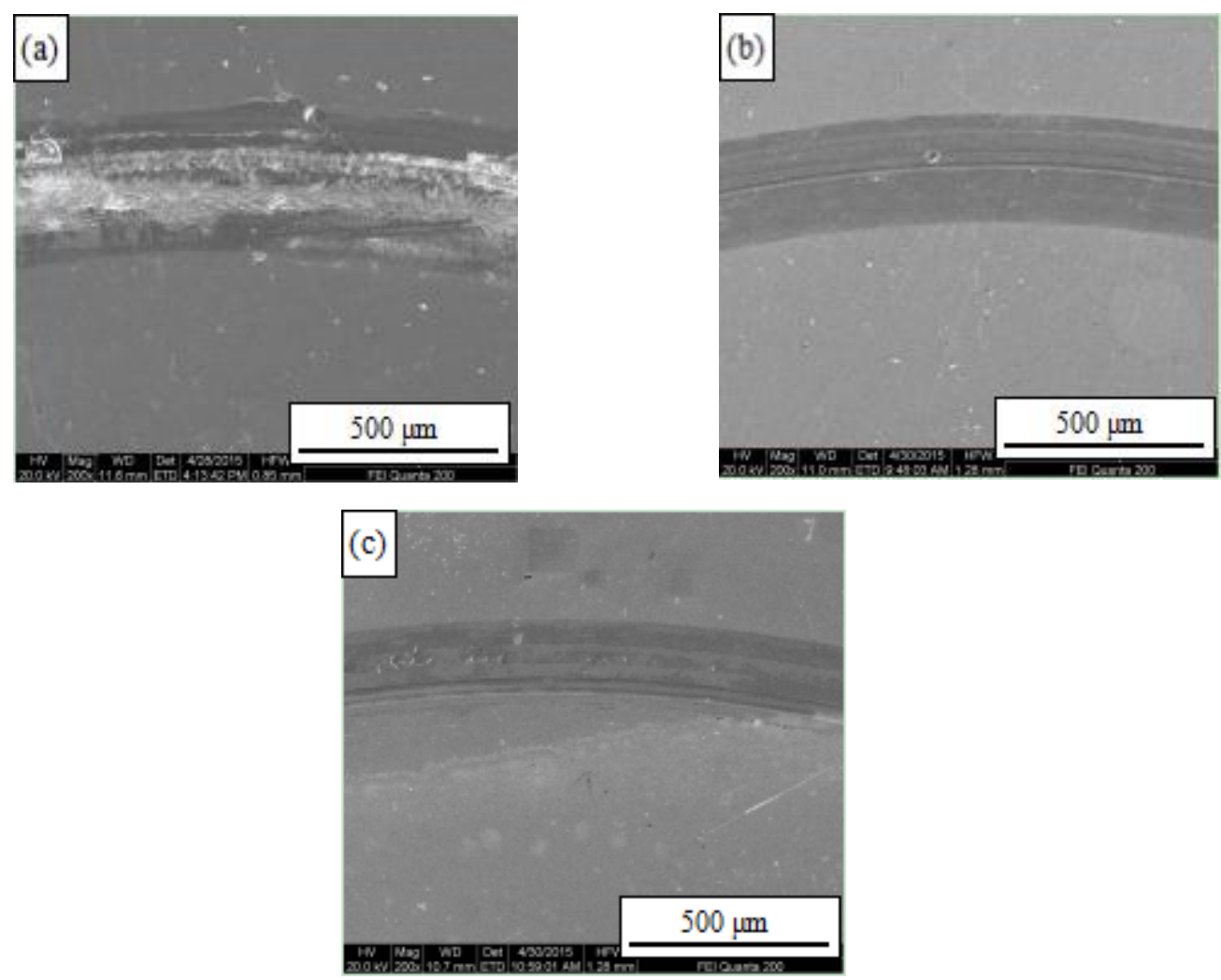

Fig.4 Wear scar morphology of TiN coatings at different friction-wear temperatures (a)RT ; (b) $200^{\circ} \mathrm{C}$; (c) $400^{\circ} \mathrm{C}$

\section{Conclusions}

(1) The friction coefficient and wear-volume of TiN coating at $200^{\circ} \mathrm{C}$ were lower than that of the friction coefficient and wear-volume at room temperature or $400^{\circ} \mathrm{C}$. The wear resistance of the coating was best at $200^{\circ} \mathrm{C}$.

(2) The wear mechanism is mainly abrasive wear. Oxidation wear occurs at the $400^{\circ} \mathrm{C}$.

\section{Acknowledgements}

The authors express their gratitude to the financial support of the National Natural Science Foundation of China (No.51365041).

\section{References}

[1] Dai Dahuang, Dai Mingjiang, Hou Huijun,etc. Functional Thin Films and Deposition Technology. Metallurgical Industry Press, Beijing, 2013.

[2] Chuang Wan Kim, Kwang Ho Kim. Anti-oxidation properties of TiAlN film prepared by plasma-assisted chemical vapor deposition and roles of Al, J.Thin Solid Films. 1997,307 113-119.

[3] Wang Fuzhen. The development of ion plating process, J. Metal Heat Treatment Abroad. 1997 (2) 27-31. 
[4] Tan Jiajun, Li Guojun. The present situation and development of metal materials heat treatment technology at home and abroad. National Defend Industry Press, Beijing, 1995.

[5] Chang Y Y, Yang S M. High temperature oxidation behavior of multicomponent Ti-Al-Si-N coatings,J. Thin Solid Films. 2010, 518(21) S34-S37.

[6] Zhu Changjun, Chen Kanghua, Wang Shequan,etc. Effects of gradient substrate structure on oxidation resistance of TiN coated cemented carbide, J. Journal of Central South University (Science and Technology). 2011,42(10) 2984-2989.

[7] Chung Wan Kim, Kwang Ho Kim. Anti-oxidation properties of TiAlN film prepared by plasma-assisted chemical vapor deposition and roles of Al,J. Thin Solid Films. 1997, 307 113-119. 